\title{
Mixing and Oxygen Transfer Characteristics of a Microplate Bioreactor with Surface-Attached Microposts
}

\author{
Justin Fisher ${ }^{1}$, Travis Gurney ${ }^{2}$, Jay Fisher ${ }^{3}$, Brittany Mason ${ }^{2}$, and William. J. Kelly ${ }^{1}$ \\ ${ }^{1}$ Villanova University \\ ${ }^{2}$ Redbud Labs \\ ${ }^{3}$ Redbud Labs
}

June 5, 2020

\begin{abstract}
Bioprocess optimization for cell-based therapies is a resource heavy activity. To reduce the associated cost and time, it is advantageous to carry out process development in small volume systems, with the caveat that such systems be predictive for process scaleup. The transport of oxygen from the gas phase into the culture medium, characterized using the volumetric mass transfer coefficient, $\mathrm{k}_{\mathrm{L}}$ a, has been identified as a critical parameter for predictive process scaleup. In both large- and small-scale bioreactors, $\mathrm{k}_{\mathrm{L}}$ a is controlled via mixing, with the method employed dependent upon the size of the reactor. However, existing microplate bioreactor platforms, beneficial for their low working volumes and throughput and automation capabilities, struggle to achieve desired $\mathrm{k}_{\mathrm{L}}$ a for mammalian cell cultures. Here, we describe the development and testing of a 96-well microplate with integrated Redbud Posts to provide mixing and thus enhanced $\mathrm{k}_{\mathrm{L}} \mathrm{a}$. Mixing characteristics were investigated, with actuating Redbud Posts shown (visually) to increase convective transport while producing enhanced $\mathrm{k}_{\mathrm{L}} \mathrm{a}$, providing means to mimic macroscale mammalian cell growth conditions at the microscale. Improved cell growth rates with mixing was demonstrated for two cell types, indicating the potential for this technology to play a valuable role in early stage bioprocess development and optimization.
\end{abstract}

\section{Introduction}

Traditionally, bioreactor performance is quantified by considering the critical transport processes and the biochemical conversion process itself [1]. Since most industrial bioprocesses are aerobic, oxygen is a limiting nutrient for cell growth and metabolic production; thus, oxygen transport into the liquid phase is a limiting factor in bioreactor and overall process performance [2]. It is therefore critical to maintain adequate transport of oxygen from the gas phase into the culture medium. Commonly, characterization of bioreactor oxygen transport is presented as the volumetric mass transfer coefficient, $\mathrm{k}_{\mathrm{L}}$ a which can be used to compare oxygen transfer performance from the microscale to industrial volumes $[2,3]$ and is an established criterion for predictive process scale-up $[4,5]$.

With the recent development of cell-based therapies to treat a wide range of unmet clinical needs, pharmaceutical companies have significant pressure to introduce new products to the market as quickly as possible [6]. When developing new therapies, early stage process development and optimization requires extensive screening of culture conditions to maximize cell growth and viability, with thousands of experiments optimized across hundreds of variables and the best performing conditions transferred to downstream production. This screening process is time consuming and expensive, due to the high cost of media components and often reduced cell growth of the cellular therapy cell types [7]. As a result, it is advantageous to implement a scaled development process wherein testing of the broadest parameter space takes place in the smallest possible volumes with promising candidates then transferred to larger volumes for additional testing. 
Microplates present an ideal format for early process development due to their low working volumes ( $\mu \mathrm{L}-\mathrm{nL}$ ) and throughput and automation capabilities. However, the utility of microplates for high throughput process development is limited due to poor control of oxygen transfer or $\mathrm{k}_{\mathrm{L}} \mathrm{a}\left(\mathrm{h}^{-1}\right)$ in these formats. Ideally, it would be possible to control the $\mathrm{k}_{\mathrm{L}}$ a in microplates to match those seen in larger volume mammalian cell culture systems, such as the Sartorius ambr@ 15/250 (15-250mL) and Cytiva's Wave Cellbag (2L-200L). For the former, $\mathrm{k}_{\mathrm{L}}$ a value ranges are of $0.18-7.90 \mathrm{~h}^{-1}$ and $2.15-11.52 \mathrm{~h}^{-1}$ are predicted while the latter can achieve $\mathrm{k}_{\mathrm{L}}$ a values that range from $1-60+\mathrm{h}^{-1}[8,9]$.

Mechanical shaking is the only commercially deployed solution for microplate mixing of cultures, and its utility is limited. Microplate shaking [10] induces splashing motion by overcoming surface tension. Splashing is an inertial effect, and as microplate well size decreases, the inertia of the droplet decreases, while surface tension remains the same. Thus, smaller wells require greater shaking energy (amplitude, frequency) to achieve the same mixing performance. For 96 well plates this critical threshold has been observed to be approximately 800 RPM (for a $3 \mathrm{~mm}$ shake amplitude) [10,11]. Achieving the desired results from mechanical shaking is surprisingly challenging. While $\mathrm{k}_{\mathrm{L}} \mathrm{a}$ in a conventional bioreactor improves smoothly with increasing impellor speed [12], shaking performance depends on whether the shaking is in-phase or out-of-phase. Increased frequency has little impact on out-of-phase mixing, and the harmonic frequency of microwells varies dramatically with well size and shape [11]. Due to these limitations, as well as concerns related to shear stress induced damage at high shake frequencies, commercially available incubator shakers are not marketed for use with mammalian cell culture. Shake-less methods such as acoustic mixing exists, but adoption has been limited by concerns about heating and scalability. In short, gentle microplate agitation remains a major unmet need for bioprocess discovery and development, especially for mammalian cell culture.

This research reports the development and characterization of a novel microliter scale culture plate with novel surface-attached agitation methodology. The microplate is designed for high throughput process development applications due to its operation in a 96-well culture plate with culture volume of 150-300 $\mu \mathrm{L}$ allowing for adequate sampling for bioanalysis. Evaporation of culture media during operation, which has been shown to be an issue in small volume culture reactors [13], is compensated for by operation in a high humidity environment. The oxygen transfer performance of the microreactor is benchmarked against conventional small-scale culture systems.

\section{Materials and methods}

\subsection{Microplate Bioreactor Design}

Microscale mixing is achieved by integrating Redbud Lab's MXR, a novel microfluidic mixing technology consisting of $1 \times 10^{5}$ Redbud Posts per $\mathrm{cm}^{2}$, as surface attached impellers in each well (Figure 1A). Redbud posts are approximately $50 \mu \mathrm{m}$ tall and $4 \mu \mathrm{m}$ in diameter and are made using a flexible polymer doped with magnetic material. When a magnetic field is applied, the posts experience a torque that works to align their dominant axis with the magnetic field, effectively creating an array of micro-stir bars with one end attached to the surface. The magnetic fields used to drive Redbud Posts are generated by a Redbud Stage (Redbud Labs, RBS-CUST-MWP) modified to accept a multiwell plate (Figure 1B.). The stage provides control over the actuation rate of the posts and has been modified further for compatibility with an incubator for environmental controls (temperature, humidity, \%CO2, etc.).

Multi-well chips (Redbud Labs, MXR-CUST-MWP(-96)) designed to evaluate planar mixing were prepared using RBL-posts affixed to an acrylic substrate (RBL proprietary method). Biocompatible adhesive spacers were cut with $\mathrm{CO}_{2}$ laser to model standard 96-well XY dimensions. An acrylic lid with fluid delivery ports was affixed atop the spacer to seal the wells resulting in 4 identical chambers with $16 \mu \mathrm{L}$ volumes $(6.73 \mathrm{~mm}$ well diameter, and $0.4 \mathrm{~mm}$ spacer height

\subsection{Planar (XY) Mixing Evaluation}

To demonstrate the mixing produced by active posts at the macroscale, we have developed planar and axial mixing assays wherein a colored liquid is added to a chamber/well containing a clear liquid and the 
time required to mix the two is calculated. Each well within the microwell plate was filled with a clear $1 \%$ solution of Triton X-100 (Thermo Scientific 85111). Afterward, a diluted blue food dye solution was prepared (McCormick) and a volume of $4 \mu \mathrm{L}$ was delivered via pipet to the well. The 4 -well chip was then placed over a 1-inch drive magnet $(120 \mathrm{mT})$. At this time, the drive system was engaged at the pre-determined $\mathrm{rpm}(3000,6000,9000)$, or left off in the case of diffusion. Videos of the four independent mixing wells driven simultaneously with identical drive conditions were captured using LCD digital microscope. The data collected via mixing video analysis was analyzed using the relative mixing index (RMI) as outlined in Hashmi, 2014 [14]. A computer program was written to pull in each frame of a video, select the appropriate ROI, and perform the analysis for each well in the frame. For this study, the threshold for a mixed state was set at an RMI of 0.85 . The resulting graphs show the average RMI for each independent drive speed evaluation $(n=4)$.

\subsection{Vertical Transport Mixing Evaluation}

Multi-well plates (96-well) were designed to evaluate vertical transport in cell culture plates. Plates were prepared using RBL-posts affixed to an acrylic substrate (RBL proprietary method). Biocompatible adhesive spacers were cut with $\mathrm{CO}_{2}$ laser to model 96 -well XY dimensions. Using these spacers, the RBL posts were bonded to the underside of clear no-bottom 96-well microplates (Greiner Bio One 655000), creating an openwell chamber with RBL posts covering the floor of the wells. Each well was first filled with $200 \mu \mathrm{L}$ clear $1 \%$ solution of Triton X-100 (Thermo Scientific 85111) and then the multi-well plate was placed over a 1-inch drive magnet $(120 \mathrm{mT})$. Afterward, a $7.5 \mu \mathrm{L}$ volume of dilute blue food dye was delivered via pipet along the well periphery and allowed to settle. At this time, the drive system was engaged at the appropriate rpm $(3000,6000,9000)$ and real-time videos were captured using LCD digital microscope. Quantitative analysis of the axial transport mixing videos was performed by determining the number of pixels the indicator dye traveled from the established baseline boundary. These values were calculated at each selected time interval (1 min.) and the distance traveled was reported in millimeters.

\subsection{Oxygen Mass Transfer Coefficient Measurement}

Dissolved Oxygen (DO) measurement was performed using OXR50 Retractable Fiber Oxygen Microsensors (Pyroscience, Aachen, Germany), along with a standard optical temperature (Pyroscience, Aachen, Germany), which were connected to a FireStingO2 optical oxygen meter (Pyroscience, Aachen, Germany). Signals were analyzed using FireSting Logger software (Pyroscience, Aachen, Germany). Experiments at each condition were performed in triplicate.

The oxygen mass transfer coefficient, $\mathrm{k}_{\mathrm{L}} \mathrm{a}$, for the microreactor was determined using the dynamic gassing out method (without cells) as described in Dunn \& Einsele, 1975 [15]. Initially, the microbioreactor was deoxygenated by continuously sparging with nitrogen gas until the dissolved oxygen concentration dropped to near zero. Air was then sparged into the system, and the increase in dissolved oxygen concentration was measured until the system returned to a steady-state oxygen concentration. During the reoxygenation step, the rate of at which the dissolved oxygen concentration changes is governed by the following equation (1) where $\mathrm{C}_{\mathrm{L}}{ }^{*}$ is the oxygen saturation concentration in the liquid phase at the gas-liquid interface $[4,16]$.

$\frac{d C_{L}}{\mathrm{dt}}=k_{L} a\left(C_{L}^{*}-C_{L}\right)-Q_{O 2} X(1)$

Thus, equation (1) can be integrated from time $t_{1}$ to $t_{2}$ and $k_{L}$ a can be determined from the slope of the graph of $l\left(\frac{C_{L 0}-C_{L}}{C_{L 0}-C_{s}}\right)$ vs $t$ where $\mathrm{C}_{\mathrm{s}}$ is the final steady-state dissolved oxygen concentration.

\subsection{Chinese Hamster Ovary (CHO) Cell Expansion}

CHO-S cells (Gibco R80007) were cultured in Freestyle CHO expression medium (Gibco 12651014) supplemented with 8 mM L-glutamine (Gibco 25030081), 0.1\% Kolliphor P188 (Sigma 15759), and 0.5X Pen/Strep (Gibco 15140122). Cells (passage 3-7) were transferred from active culture in 125-mL shake flask (DWK Life Sciences WPFPC0125S) and seeded in RBL bioreactor 96-well microplate at a concentration of 150,000 cells/mL per well with a volume of $300 \mu \mathrm{L}$. The plates were then sealed with a breathable rayon-acrylate film (Thermo Scientific 241205) to prevent evaporative loss during culture. Drive system was set to duty-cycle 
(10 min. ON, 50 min. OFF) at a selected rate $(6000 \mathrm{RPM})$ and placed inside a cell culture incubator at $37^{\circ} \mathrm{C}$ with a humidified atmosphere at $8 \% \mathrm{CO}_{2}$. Total protein values for each culture condition at the end of a 72-h culture period were determined by Bradford protein assay kit (Thermo Scientific 23246) following complete cell lysis. The resulting protein values were reported as cell concentration (cells/mL) after comparison to standard protein curve obtained from known CHO-S cell counts.

\subsection{CHO Cell Lysis and Determination of Cell Number}

Upon completion of a $72 \mathrm{hr}$ growth cycle, the RBL drive system was disengaged and cells were allowed to settle. Growth media was removed from the culture wells and transferred to labeled $0.5 \mathrm{~mL}$ tubes. The media/cell supernatant was centrifuged at $1000 \mathrm{rpm}$ for $5 \mathrm{~min}$. to pellet any intact suspended cells remaining in growth media. At this time, a volume of $100 \mu \mathrm{L}$ Triton X-100 (1\%) was added to each well containing the settled cells and gently mixed by pipet to disassociate any large clusters. This plate was left undisturbed for $10 \mathrm{~min}$. to ensure complete lysis. Meanwhile, the supernatant/media was removed from $0.5 \mathrm{~mL}$ tubes while being careful not to disturb the pellet. The lysed cell solution $(100 \mu \mathrm{L})$ was transferred to its corresponding $0.5 \mathrm{~mL}$ tube, vortexed (2-3 pulses), and allowed to incubate for another $5 \mathrm{~min}$. to complete lysis of any residual cells from media suspension. After this period, $0.5 \mathrm{~mL}$ tubes were centrifuged at $5,000 \mathrm{rpm}$ for 5 min. to spin down any cell debris and leaving soluble protein in supernatant. A volume of $10 \mu \mathrm{L}$ from the supernatant solution was transferred to a clear 96-well plate for protein analysis. The detergent compatible Bradford protein assay was run according to manufacturer recommended microplate procedures and read at $595 \mathrm{~nm}$ using multi-mode plate reader (BioTek Synergy LX). In order to relate soluble protein absorbance values to cell count, lysate prepared from cell populations with known concentrations ranging from 0 to 1 $\mathrm{X} 10^{\wedge} 6$ cells $/ \mathrm{mL}$ was evaluated for protein content. A standard curve of soluble protein to cell count was generated and cell populations are reported as cells $/ \mathrm{mL}$.

\subsection{T Cell Expansion}

$\mathrm{CD} 4^{+}$Naïve cells were obtained from Astarte Biologics (Astarte Biologics, Washington, USA) and were cultured in X-VIVO serum free T-Cell medium (Lonza, New Jersey, USA). This medium was additionally supplemented with recombinant human interleukin 2 (IL-2), recombinant human interleukin 7 (IL-7), and recombinant human interleukin 15 (IL-15) (Miltenyi Biotech GmbH, Germany) at various concentrations on Day 3. In the ' 000 ' condition, medium was supplemented with the following interleukin concentrations: IL-2 $(1 \mathrm{ng} / \mathrm{mL})$, IL-7 (6 ng/mL), IL-15 (6 ng/mL). In the '110' condition, medium was supplemented with the following interleukin concentrations: IL-2 $(10 \mathrm{ng} / \mathrm{mL})$, IL-7 $(36 \mathrm{ng} / \mathrm{mL})$, IL-15 $(6 \mathrm{ng} / \mathrm{mL})$. T cells were combined with anti-CD3/anti-CD28 DynaBeads(r) (Gibco, Waltham, MA) in bead:T cell ratio of 1:1. Cells were then seeded at 166,667 cells per $\mathrm{mL}$ in the described surface-attached microplate with $300 \mu \mathrm{L}$ culture medium. The day of seeding is referred to as Day 0 of the expansion. Cell samples were obtained in the process daily starting on Day 3 for enumeration.

During expansion, mixed condition was subject to agitation via surface-attached microposts which were agitated via magnetic motor. The motor was operated at $4000 \mathrm{rpm} 5$ minutes on 55 minutes off cycle continuously throughout the duration of expansion.

\subsection{Statistical Analysis}

Descriptive statistics showing means, and standard deviations for cell expansion were calculated using Mi$\operatorname{crosoft}($ Excel $($ ) data analysis.

\section{Results}

\subsection{Investigation of Oxygen Mass Transfer Coefficient in 96-Well Microreactor}

As previously discussed, $\mathrm{k}_{\mathrm{L}}$ a has been established as a critical parameter for predictive process scale- up $[17,18]$ and optimal bioreactor performance. Figure 2 shows a comparison between the dissolved oxygen recovery curve (Figure 2A.) and estimated $k_{L}$ a values by equation (2) in a mixed microbioreactor versus an unmixed microbioreactor as measured by the dynamic gassing method (Figure 2B.). In this comparison, there 
was an increased rate of oxygen recovery following deoxygenation when mixed via Redbud Labs proprietary micro-posts than via diffusion alone (no mixing). This increased oxygen recovery corresponded to a calculated $\mathrm{k}_{\mathrm{L}}$ a value of $42.48 \mathrm{~h}^{-1}$ in the mixed condition when mixed at $7400 \mathrm{rpm}$ versus $21.24 \mathrm{~h}^{-1}$ in the unmixed at a well volume of $150 \mu \mathrm{L}$.

To investigate the magnetic agitated micro-post's capability to improve oxygen transfer in a 96 -well microbioreactor, the $\mathrm{k}_{\mathrm{L}}$ a was determined in a single well at different magnetic rotational speeds (0-9000 rpm). For the unmixed control conditions, the observed $\mathrm{k}_{\mathrm{L}}$ a values ranged from 3.72 to $12.47 \mathrm{~h}^{-1}$ decreasing as culture volume increased, a variation which is consistent with variation seen in similar sized microtiter plates [5] and shake flasks [19].

In the 96 well plate, higher $\mathrm{k}_{\mathrm{L}}$ a values were obtained as the magnetic rotational speed was increased (Figure $2 \mathrm{C})$ ranging from the unmixed $\mathrm{k}_{\mathrm{L}}$ a values to $89.28 \mathrm{~h}^{-1}(9000 \mathrm{rpm}, 200 \mu \mathrm{L})$. At $3500 \mathrm{rpm}$ the observed $\mathrm{k}_{\mathrm{L}} \mathrm{a}$ values were $14.64 \mathrm{~h}^{-1}(150 \mu \mathrm{L}), 8.88 \mathrm{~h}^{-1}(200 \mu \mathrm{L})$, and $9.12 \mathrm{~h}^{-1}(300 \mu \mathrm{L})$. At $6500 \mathrm{rpm}$ the observed $\mathrm{k}_{\mathrm{L}}$ a values were $34.2 \mathrm{~h}^{-1}(150 \mu \mathrm{L}), 33.6 \mathrm{~h}^{-1}(200 \mu \mathrm{L})$, and $19.41 \mathrm{~h}^{-1}(300 \mu \mathrm{L})$. At $9000 \mathrm{rpm}$ the observed $\mathrm{k}_{\mathrm{L}}$ a values were $88.20 \mathrm{~h}^{-1}(150 \mu \mathrm{L}), 89.28 \mathrm{~h}^{-1}(200 \mu \mathrm{L})$, and $37.20 \mathrm{~h} \mathrm{~h}^{-1}(300 \mu \mathrm{L})$. This observed variation in $\mathrm{k}_{\mathrm{L}} \mathrm{a}$ with increased rotational speed is comparable to the change observed with increased shaking frequency in comparable 200 $\mu \mathrm{L}$ microtiter plates $[5,20]$. Initially as the rotational speed increased, there is not a substantial increase in $\mathrm{k}_{\mathrm{L}} \mathrm{a}$. However, there is an observed critical rotational speed, beyond which $\mathrm{k}_{\mathrm{L}}$ a increases exponentially.

\subsection{Influence of Well Fill Volume on $k_{L} a$}

To investigate the influence of the fill volume on $\mathrm{k}_{\mathrm{L}} \mathrm{a}$, the $\mathrm{k}_{\mathrm{L}}$ a was measured at three well volumes (150, $200,300 \mu \mathrm{L}$ ). As seen in Figure $2 \mathrm{C}$, at a fill volume of $150 \mu \mathrm{L}, \mathrm{k}_{\mathrm{L}}$ a values ranged from $12.37 \mathrm{~h}^{-1}$ (Unmixed), $14.64 \mathrm{~h}^{-1}(3500 \mathrm{rpm}) 34.2 \mathrm{~h}^{-1}(6500 \mathrm{rpm})$ to $88.2 \mathrm{~h}^{-1}(9000 \mathrm{rpm})$. At a fill volume of $200 \mu \mathrm{L}, \mathrm{k}_{\mathrm{L}}$ a values ranged from $9.60 \mathrm{~h}^{-1}$ (Unmixed), $8.88 \mathrm{~h}^{-1}(3500 \mathrm{rpm}), 33.6 \mathrm{~h}^{-1}(6500 \mathrm{rpm})$ to $89.28 \mathrm{~h}^{-1}$ (9000 rpm). At a fill volume of $300 \mu \mathrm{L}, \mathrm{k}_{\mathrm{L}}$ a values ranged from $3.72 \mathrm{~h}^{-1}$ (Unmixed), $9.12 \mathrm{~h}^{-1}$ (3500 rpm), $19.44 \mathrm{~h}^{-1}$ (6500 $\mathrm{rpm})$ to $37.2 \mathrm{~h}^{-1}(9000 \mathrm{rpm})$. As fill volume increased, there was a decrease in observed $\mathrm{k}_{\mathrm{L}} \mathrm{a}$ at a given rotational speed, a trend consistent with comparable sized microreactors [5,20,21]. The observed trend is expected, due to $\mathrm{k}_{\mathrm{L}}$ a being volume specific. Further, as discussed there is a critical rotational speed, beyond which there is an exponential increase in $\mathrm{k}_{\mathrm{L}} \mathrm{a}$. As demonstrated in Figure $2 \mathrm{C}$, this critical value is dependent on fill volume, whereby the higher the well fill volume, the higher rotational speed required to reach the exponential increase in $\mathrm{k}_{\mathrm{L}}$ a.

\subsection{Planar (XY) Mixing Analysis}

Active mixing images were taken from wells driven by RBL posts at 9,000 rpm. Frames from real-time videos were selected at intervals $\mathrm{t}=0,0.5,1,1.5$, and 2 min. Diffusion images without active mixing (static RBL posts) were selected from time-lapse series at intervals $\mathrm{t}=0,30,60,90$, and $120 \mathrm{~min}$. As demonstrated in Figure $3 \mathrm{~A}$, homogeneity was achieved quicker when mixed via micropost agitation ( $\mathrm{t}=2 \mathrm{~min}$ ) verse diffusion alone $(\mathrm{t}=120 \mathrm{~min})$, indicating micropost agitation offers greater radial mixing capabilities than diffusion alone.

Relative Mixing Index (RMI) as outlined by Hashmi, 2014 [14] was utilized to compare the active mixing profile of three different rotational mixing speeds: 3000, 6000, and $9000 \mathrm{rpm}$. As demonstrated in Figure 3B, complete mixing was achieved sooner (90 s) at the highest rotational speed (9000 rpm), however the moderate mixing speed $(6000 \mathrm{rpm})$ achieved complete mixing the slowest $(215 \mathrm{~s})$.

\subsection{Vertical Transport Mixing Analysis}

To establish the micropost ability to achieve sufficient axial mixing, video analysis (Figure 4A) of vertical transport as a function of time was utilized. Following 10 minutes of active agitation, microwells achieved complete vertical transport, indicated by presence of dye at the liquid surface of well; whereas diffusion alone had very little vertical transport. To further confirm the video analysis, quantitative analysis of the distance traveled indicated that when compared to diffusion, active microposts achieve higher levels of vertical transport, increasing with increasing rotational speeds (Figure 4B). After 10 minutes of active 
agitation, at $9000 \mathrm{rpm}$, transport dye had traveled the greatest distance $(4.3 \mathrm{~mm})$ compared to $2.93 \mathrm{~mm}$ $(6000 \mathrm{rpm}), 1.88 \mathrm{~mm}(3000 \mathrm{rpm})$. Under active agitation, transport dye had greater distance traveled all rotational speeds than that during diffusion alone $(1.23 \mathrm{~mm})$ indicating microbioreactor has increased axial transport for nutrient transport.

\subsection{CHO-S Cell Growth Analysis}

CHO-S cells were cultured for 72 hours in three culture vessels: Standard 96-well plate (Control), Redbud Labs Microplate (No Mixing) and Redbud Labs Microplate (Mixing @ $6000 \mathrm{rpm}$ ). There was an observed increase in cell growth when cultured in an agitated Redbud Labs vessel $(566,000$ cells $/ \mathrm{mL})$ compared to both the unmixed Redbud Labs vessel $(499,214$ cells $/ \mathrm{mL})$ and the standard 96 -well plate $(432,071 \mathrm{cells} / \mathrm{mL})$ (Figure 5A). As established, vessels agitated with Redbud Labs microposts have increased oxygen transport capabilities, thus it is expected that cell growth would be increased in such vessels. Further, there was an observed increase in cell growth in both vessels containing Redbud posts compared to the standard 96-well plate, suggesting post microenvironment promotes increase cell growth.

\subsection{T Cell Growth Analysis}

$\mathrm{CD} 4^{+} \mathrm{T}$ cells were expanded under two different concentrations of essential interleukins, IL-2, IL-7, and IL-15 (000 or 110) which corresponded to low and high concentrations of each respectively and were either mixed via surface attached microposts or unmixed. CD4 ${ }^{+} \mathrm{T}$ cells were seeded at a concentration of 166,667 cells/mL and harvested 7 days later. The expansion kinetics for $\mathrm{T}$ cells are shown in Figure 5B. There was an observed peak cell yield on day 5 for all conditions, indicating the need for culture feed and potential further activation. When mixed, the 110 condition experienced the highest cell yield on day $5(117,500 \mathrm{cells} / \mathrm{mL})$ whereas the 000 condition had a lower day 5 cell yield $(45,000$ cells $/ \mathrm{mL})$. When unmixed, the 110 condition had the highest cell yield on day $5(72,500$ cells $/ \mathrm{mL})$ whereas the 000 condition had a lower day 5 cell yield $(45,000$ cells $/ \mathrm{mL})$. When mixed, both interleukin concentration sets $(000 \& 110)$ had higher daily cell yield than their respective unmixed conditions, until day 7 , which saw a decline in all conditions.

\section{Discussion}

We have developed a novel surface agitated $300 \mu \mathrm{L}$ microbioreactor suitable for small-scale process development. The oxygen mass-transfer coefficient, $\mathrm{k}_{\mathrm{L}} \mathrm{a}$, was characterized to range from 12 to $89 \mathrm{hr}^{-1}$ which are of similar magnitude as those commonly found in small scale reactors for mammalian cell culture $[5,20,22]$. Mixing evaluation determined the surface agitated microposts achieved increased planar (XY) mixing when compared to diffusion alone as well as decreased time to achieve complete mixing as mixing speed was increased (RMI $>0.85$ achieved between 90 to $215 \mathrm{~s}$ ). Evaluation of vertical transport mixing determined that active mixing achieved vertical homogeneity sooner than diffusion alone, supported by an increased distance traveled in active mixed wells than those achieved in a diffusion alone system. Static microplate small scale mammalian cell process development technologies have insufficient oxygen transport capabilities due to complications arising from mechanical agitation of static microplate cultures [22-24]. Thus, the developed microplate bioreactor's microenvironment overcomes such complications, and has sufficient convective flow of nutrients, which more closely resembles that of larger scale stirred tank bioreactors, as opposed to diffusional transport.

When compared to previously described microbioreactor's [3,5,21,25], our results consistently follow reported trends whereby increased agitation speed leads to an increased $\mathrm{k}_{\mathrm{L}} \mathrm{a}$, as well as increased fill volume leads to a decreased $\mathrm{k}_{\mathrm{L}}$ a. However, the increase in $\mathrm{k}_{\mathrm{L}} \mathrm{a}$ in large volume systems often reported occurs with agitation speeds an order of magnitude lower than those reported in this study. There are certainly differences in systems, with the reviewed microbioreactor being mixed via surface-attached microposts, which are agitated via a magnetic drive system. Further, in our system there are approximately 1 x $10^{5}$ Redbud Posts per $\mathrm{cm}^{2}$ therefore, agitation rate may not directly reflect the overall mixing paradigm within the culture vessel. Therefore, rather than a comparison in systems performed based on comparing trends in increased agitation speed, a more useful comparison may be to compare trends based on increasing power per unit volume values. While power input is certainly a function of the diameter of impeller, it may be useful to consider rather 
how the magnetic strength translates to power input within the fluid and the efficiency in the conversion of energy within the fluid when determining the overall power input within this culture vessel.

In our novel microbioreactor, oxygen is supplied throughout the culture via oxygen diffusion into the liquid phase at the surface gas-liquid interface. Therefore, the observed improvement in $\mathrm{k}_{\mathrm{L}} \mathrm{a}$ values in the microbioreactor at higher magnetic rotational speeds can be attributed primarily to better mixing and distribution of dissolved oxygen in the liquid phase, thus indicating the microbioreactor has an increased oxygen transport capability. Further, the observed $\mathrm{k}_{\mathrm{L}}$ a values are of the same magnitude as those commonly found in mammalian cell culture, thus there is confidence the microbioreactor is suitable for expanding mammalian cells $[8,9]$.

Preliminary results demonstrated that, in both mammalian cell types, higher cell yield was achieved in our actively mixed vessel than static cultures, indicating that the convective flow of nutrients achieved in the microbioreactor promotes increase cell growth. In the CHO cultures, there was an observed greater cell growth in both vessels, which contained RBL posts regardless of the presence of agitation, compared to a standard 96-well plate. Potentially, this is due to the presence of RBL posts acting as additional support for cell growth, allowing for cells to adhere to posts during static culture, thus creating sections of plate composing of bilayers rather than a monolayer found in standard 96 well plates.

In the $\mathrm{T}$ cell cultures, there was an observed greater cell yield when mixed, regardless of cytokine condition, than the unmixed conditions. This observed increase, while certainly due to increased oxygen transfer into the liquid; may also be due to improved convective transport of nutrient (including oxygen) into the $\mathrm{T}$ cell-bead aggregates that form. Further, there was an observed significant decline in cell yield following seed until day 4, which is hypothesized to be due to cells being cultured straight from cryopreservation, thus having a significant adaptation phase. Additionally, decline observed following day 6 of culture indicates the need for culture medium feed and potential further expansion. Further, presence of magnetic beads required for $\mathrm{T}$ cell activation alongside magnetic field for agitation led to posts knockdown (caused by magnetic bead interaction with posts) further optimization is necessary of culture expansion conditions including agitation speed and medium feed.

Across both mixed and unmixed, the 110 condition had higher daily cell yield than the 000 condition, indicating the 110 condition, which contained higher IL-2 \& IL-7 concentrations, is more suitable for cell culture than that of the 000 condition interleukin concentrations. The common $\mathrm{T}$ cell expansion factor, IL-2 has been extensively researched to evaluate effects of varying levels on cell expansion [26-28]. However, Jaleco et al., 2003 [29] found that IL-2 and IL-7 act together to promote proliferation, and is significantly more effective than using IL-2 or IL-7 alone. Further, due to IL-2 and IL-7 acting through one of the same pathways, higher levels of both cytokines (such as those found in the 110 condition) would act to enhance the effectiveness of both IL-2 and IL-7 in tandem [30], which supports the findings reported here.

The novel bioreactor developed achieves mixing and oxygen transport capabilities extending beyond those found in static small-scale culture and preliminary cell culture results suggest enhanced cell yield. Based on these results, the microenvironment found in this system is suitable for cell culture and is more closely representative of that in a traditional stirred tank bioreactor for mammalian cell culture and has potential for use in small scale process development applications.

\section{Acknowledgement}

This work was performed under a Project Award Agreement from the National Institute for Innovation in Manufacturing Biopharmaceuticals (NIIMBL) and financial assistance award 70NANB17H002 from the U.S. Department of Commerce, National Institute of Standards and Technology

\section{Conflict of interest}

Travis O. Gurney, Brittany M. Nelson Dr. Jay K. Fisher are employed by RedBud Labs

\section{References}


[1] Lübbert, A., Jørgensen, S. B., Bioreactor performance: a more scientific approach for practice. J. Biotechnol. 2001, $85,187-212$.

[2] Garcia-Ochoa, F., Gomez, E., Bioreactor scale-up and oxygen transfer rate in microbial processes: An overview. Biotechnol. Adv. 2008, 27, 153-76.

[3] Kirk, T, V., Szita, N., Oxygen transfer characteristics of miniaturized bioreactor systems. Biotechnol. Bioeng . 2013,110 , 1005-19.

[4] Doran, M. P., Mass Transfer, in: Elsevier Ltd. (Ed.)Bioprocess Engineering Principles, Academic Press, London 2013, pp. 397-444.

[5] Hermann, R., Lehmann, M., Büchs, J., Characterization of gas-liquid mass transfer phenomena in microtiter plates.Biotechnol. Bioeng. 2003, 81, 178-86.

[6] Harrison, P, R., Medcalf, N., Rafiq, A, Q., Cell therapy-processing economics: Small-scale microfactories as a stepping stone toward large-scale macrofactories. Regen. Med. 2018,13 , 159-73.

[7] Reichen, M,. Macown, J, R., Jaccard, N., Super, A. et al., Microfabricated Modular Scale-Down Device for Regenerative Medicine Process Development. PLoS. One. 2012,7 , e52246.

[8] Li, X., Scott, K., Kelly, J, W., Huang, Z,. Development of a Computational Fluid Dynamics Model for Scaling-up Ambr Bioreactors.Biotechnol. Bioprocess. Eng. 2018,23 , 710-25.

[9] Nienow, W, A., Reactor engineering in large scale animal cell culture. Cytotechnology. 2006, 50 , 9-33.

[10] Klöckner, W., Büchs, J., Advances in shaking technologies. Trends. Biotechnol. 2012, 30 , 307-14.

[11] Mitre, E., Schulze, M., Cumme, A, G., Rössler, F. et al., Turbo-mixing in microplates. J. Biomol. Screen. 2007, 12, 361-9.

[12] Xie, M., Xia, J., Zhou, Z., Chu, J. et al., Flow pattern, mixing, gas hold-up and mass transfer coefficient of triple-impeller configurations in stirred tank bioreactors. Ind. Eng. Chem. Res.2014, 53, 5941-53.

[13] El-Ali, J., Sorger, K, P., Jensen, F, K., Cells on chips.Nature 2006, 442 , 403-11.

[14] Hashmi, A., Xu, J., On the Quantification of Mixing in Microfluidics. J. Lab. Autom. 2014, 19 , 488-91.

[15] Dunn, J, I., Einseleb, A., Oxygen Transfer Coefficients by the Dynamic Method. J. appl. Chem. Biotechnol. 1975, $25,707-720$.

[16] Tribe, A, L. Briens, L, C., Margaritis, A., Determination of the volumetric mass transfer coefficient (kLa) using the dynamic "gas out-gas in" Method: Analysis of errors caused by dissolved oxygen probes. Biotechnol. Bioeng. 1995, 46 , 388-92.

[17] Islam, S, R., Tisi, D., Levy, S, M., Lye, J, G., Scale-up of Escherichia coli growth and recombinant protein expression conditions from microwell to laboratory and pilot scale based on matched k La.Biotechnol. Bioeng. 2008, $99,1128-39$.

[18] Islam, S, R., Tisi, D., Levy, S, M., Lye, J, G., Framework for the Rapid Optimization of Soluble Protein Expression in Escherichia coli Combining Microscale Experiments and Statistical Experimental Design.Biotechnol. Prog. 2007, 23 , 785-93.

[19] Wittmann, C., Kim, M, H., John, G., Heinzle, E., Characterization and application of an optical sensor for quantification of dissolved O2 in shake-flasks. Biotechnol. Lett. 2003,25 , 377-80.

[20] John, T, G., Klimant, I., Wittmann, C., Heinzle, E., Integrated optical sensing of dissolved oxygen in microtiter plates: A novel tool for microbial cultivation. Biotechnol. Bioeng. 2003, 81 , 829-36.

[21] Duetz, A, Q., Microtiter plates as mini-bioreactors: miniaturization of fermentation methods. Trends. Microbiol. 2007,15 , 469-75. 
[22] Betts, I, J., Baganz, F., Microbial Cell Factories Miniature bioreactors: current practices and future opportunities. Microb. Cell. Fact. 2006, 5, 21.

[23] Micheletti, M., Barrett, T., Doig, S., Baganz, F. et al., Fluid mixing in shaken bioreactors: Implications for scale-up predictions from microlitre-scale microbial and mammalian cell cultures. Chem. Eng. Sci. 2006, $61,2939-49$.

[24] Büchs, J., Introduction to advantages and problems of shaken cultures. Biochem. Eng. J. , 2001, 7, 91-88.

[25] Zhang, Z., Szita, N., Boccazzi, P., Sinskey, J, A., Jensen, F, K., A well-mixed, polymer-based microbioreactor with integrated optical measurements. Biotechnol. Bioeng. 2006, 93 , 286-96.

[26] Litvinova, S, L., Sokhonevich, A, N., Gutsol, A, A., Kofanova, A, K., The influence of immunoregulatory cytokines IL-2, IL-7, and IL-15 upon activation, proliferation, and apoptosis of immune memory T-cells in vitro. Cell. Tissue. Biol. 2013, 7, 539-44.

[27] Ganusov, V, V., Milutinović, D., De Boer, J, R., IL-2 Regulates Expansion of CD4 + T Cell Populations by Affecting Cell Death: Insights from Modeling CFSE Data. J. Immunol. 2007, 179 , 950-7.

[28] Deenick, K, E., Gett, V, A., Hodgkin, D, P., Stochastic Model of T Cell Proliferation: A Calculus Revealing IL-2 Regulation of Precursor Frequencies, Cell Cycle Time, and Survival. J. Immunol.2003, 170 , 4963-72.

[29] Jaleco, S., Swainson, L, Dardalhon, V., Burjanadze M, et al., Homeostasis of Naive and Memory CD4 + T Cells: IL-2 and IL-7 Differentially Regulate the Balance Between Proliferation and Fas-Mediated Apoptosis. J. Immunol. 2003, $171,61-8$.

[30] Rochman, Y., Spolski, R., Leonard, J, W., New insights into the regulation of $\mathrm{T}$ cells by $\gamma$ family cytokines. Nat. Rev. Immunol.2009, 9 , 480-90.

\section{Figures}

\section{** Attached as separate files**}

\section{Figure legends}

Figure 1. Microplate Bioreactor Design. A . MXR is an array of Redbud Posts (50 um length, $4 \mu \mathrm{m}$ diameter) molded from a single film. The film is mounted on an acrylic backing for rigidity and topped with a laser cut double sided adhesive to define the chamber mask. The assembled "chip" can be integrated into No Bottom Microplates by peeling off the adhesive liner covering the mask and mounting under the microplate. B. RedBud Stage modified to accept multiwell microplate bioreactor. The stage provides control over the actuation rate of posts and is compatible with incubator for environmental control.

Figure 2. Oxygen Mass Transfer Coefficient Evaluation in Microplate Bioreactor. A . Comparison of Dissolved Oxygen Profile demonstrating an increased rate of oxygen recovery following deoxygenation when mixed via Redbud Labs microposts than via diffusion alone (no mixing). B. Linear (by logarithmic scale) Prediction of $\mathrm{k}_{\mathrm{L}}$ a between Unmixed and Mixed (7400 rpm) microplate reactors at a culture volume of 150 $\mu \mathrm{L}$ corresponding to $\mathrm{k}_{\mathrm{L}}$ a values of $42.48 \mathrm{~h}^{-1}$ (Mixed) and $21.24 \mathrm{~h}^{-1}$ for diffusion alone. C $\mathrm{k}_{\mathrm{L}}$ a as a function of magnet rotational speed in the microbioreactor for three culture volumes $(150 \mu \mathrm{L}, 200 \mu \mathrm{L}, 300 \mu \mathrm{L})$. At $150 \mu \mathrm{L}, \mathrm{k}_{\mathrm{L}}$ a values ranged from $12.37 \mathrm{~h}^{-1}$ (Unmixed), $14.64 \mathrm{~h}^{-1}(3500 \mathrm{rpm}) 34.2 \mathrm{~h}^{-1}(6500 \mathrm{rpm})$ to $88.2 \mathrm{~h}$ ${ }^{-1}(9000 \mathrm{rpm})$. At $200 \mu \mathrm{L}, \mathrm{k}_{\mathrm{L}}$ a values ranged from $9.60 \mathrm{~h}^{-1}$ (Unmixed), $8.88 \mathrm{~h}^{-1}$ (3500 rpm), $33.6 \mathrm{~h}^{-1}(6500$ $\mathrm{rpm})$ to $89.28 \mathrm{~h}^{-1}(9000 \mathrm{rpm})$. At $300 \mu \mathrm{L}, \mathrm{k}_{\mathrm{L}}$ a values ranged from $3.72 \mathrm{~h}^{-1}$ (Unmixed), $9.12 \mathrm{~h}^{-1}$ (3500 rpm), $19.44 \mathrm{~h}^{-1}(6500 \mathrm{rpm})$ to $37.2 \mathrm{~h}^{-1}(9000 \mathrm{rpm})$.

Figure 3. Planar (XY) Mixing Analysis. A . Comparison of planar mixing rates in wells driven by RBL posts (active mixing) versus diffusion alone (static RBL posts). Homogeneity was achieved in agitated wells in 2 minutes, verse 120 minutes in the wells mixed via diffusion alone. B . Average Relative Mixing Index 
(Outlined by Hashmi, 2014 [14]) of the active mixing wells (3000, 6000, $9000 \mathrm{rpm}$ ) over time. Wells are considered fully mixed when they achieve a RMI of 0.85 . At $3000 \mathrm{rpm}$, complete mixing was achieved after $180 \mathrm{~s}$, whereas at $6000 \mathrm{rpm}$ complete mixing was achieved after $215 \mathrm{~s}$ and at $9000 \mathrm{rpm}$ complete mixing was achieved after $90 \mathrm{~s}$.

Figure 4. Vertical Transport Mixing Analysis. A . Video Evaluation of Vertical Transport. Images displayed are selected frames from real-time video at timepoints $\mathrm{t}=0,2.5,5,7.5$, and $10 \mathrm{~min}$. One well (shown left) includes active RBL posts, whereas the well on the right has static RBL posts to establish diffusion baseline. The RBL drive magnet was placed below the wells, operating at $9000 \mathrm{rpm}$. B . Vertical distance traveled comparison between active agitation $(3000,6000,9000 \mathrm{rpm})$ and diffusion alone. After 10 minutes, at 9000 rpm dye traveled $4.23 \mathrm{~mm}$ compared to $2.93 \mathrm{~mm}(6000 \mathrm{rpm}), 1.88 \mathrm{~mm}(3000 \mathrm{rpm})$ and $1.23 \mathrm{~mm}$ (diffusion alone).

Figure 5. Evaluation of Mammalian Cell Growth in Microbioreactor. A. Comparison of Chinese Hamster Ovary $(\mathrm{CHO})$ growth results following $72 \mathrm{hr}$ expansion in three culture vessels. When expanded in the presence of active Redbud posts, increased CHO cell growth was observed $(566,000$ cells $/ \mathrm{mL})$ compared to both standard 96-well plate $(432,071 \mathrm{cells} / \mathrm{mL})$ and the unmixed Redbud posts $(499,214 \mathrm{cells} / \mathrm{mL})$. B. Comparison of CD4 ${ }^{+}$Cell growth results in active (mixed) Redbud posts or static (unmixed) Redbud posts at two cytokine levels $(110,000)$. Highest cell yield was observed on day 5 where 110 condition had higher cell yields $(117,500$ cells $/ \mathrm{mL}$ mixed, 72,500 cells $/ \mathrm{mL}$ unmixed) compared to 000 condition $(45,000$ cell $/ \mathrm{mL}$ mixed, 45,000 cells/mL unmixed).
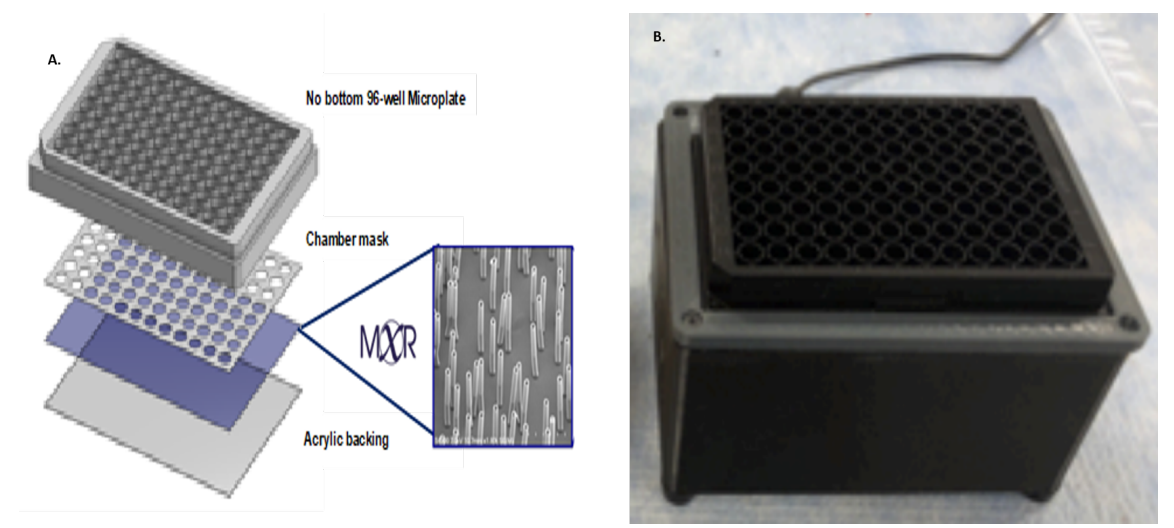

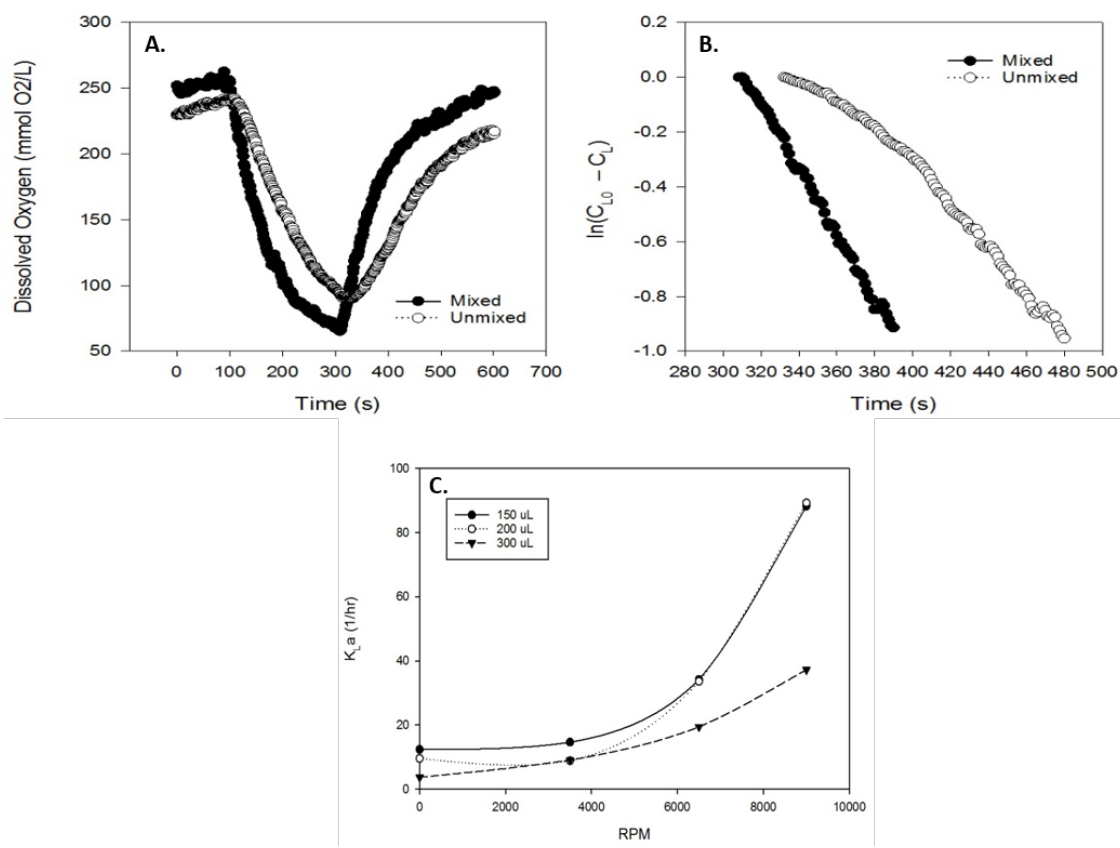

A.

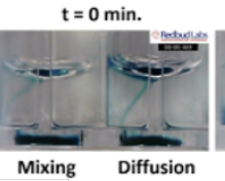

$\mathrm{t}=\mathbf{2 . 5} \mathrm{min}$.
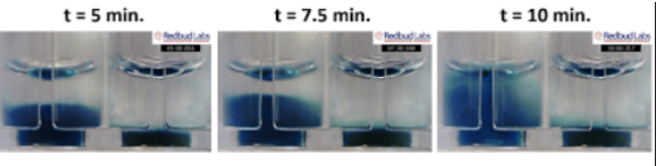

B.

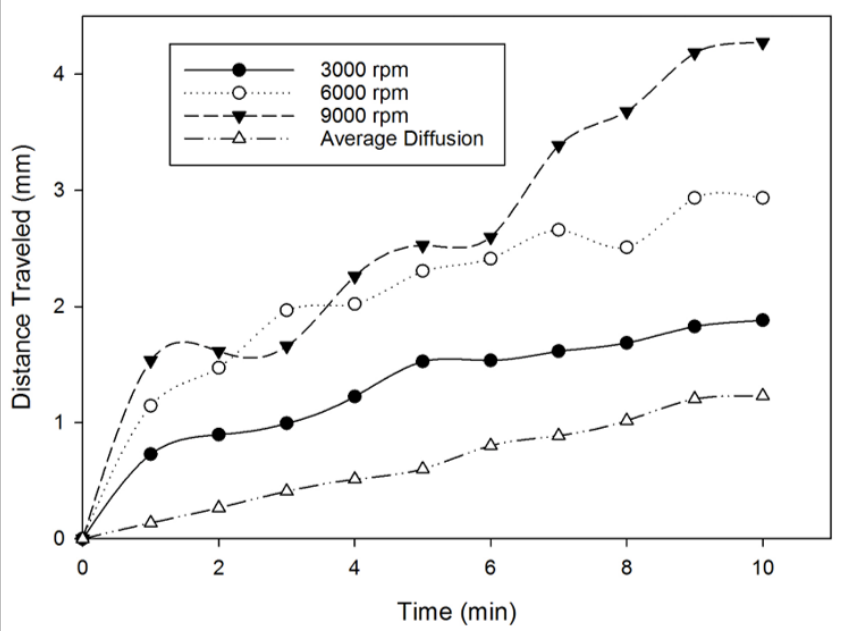



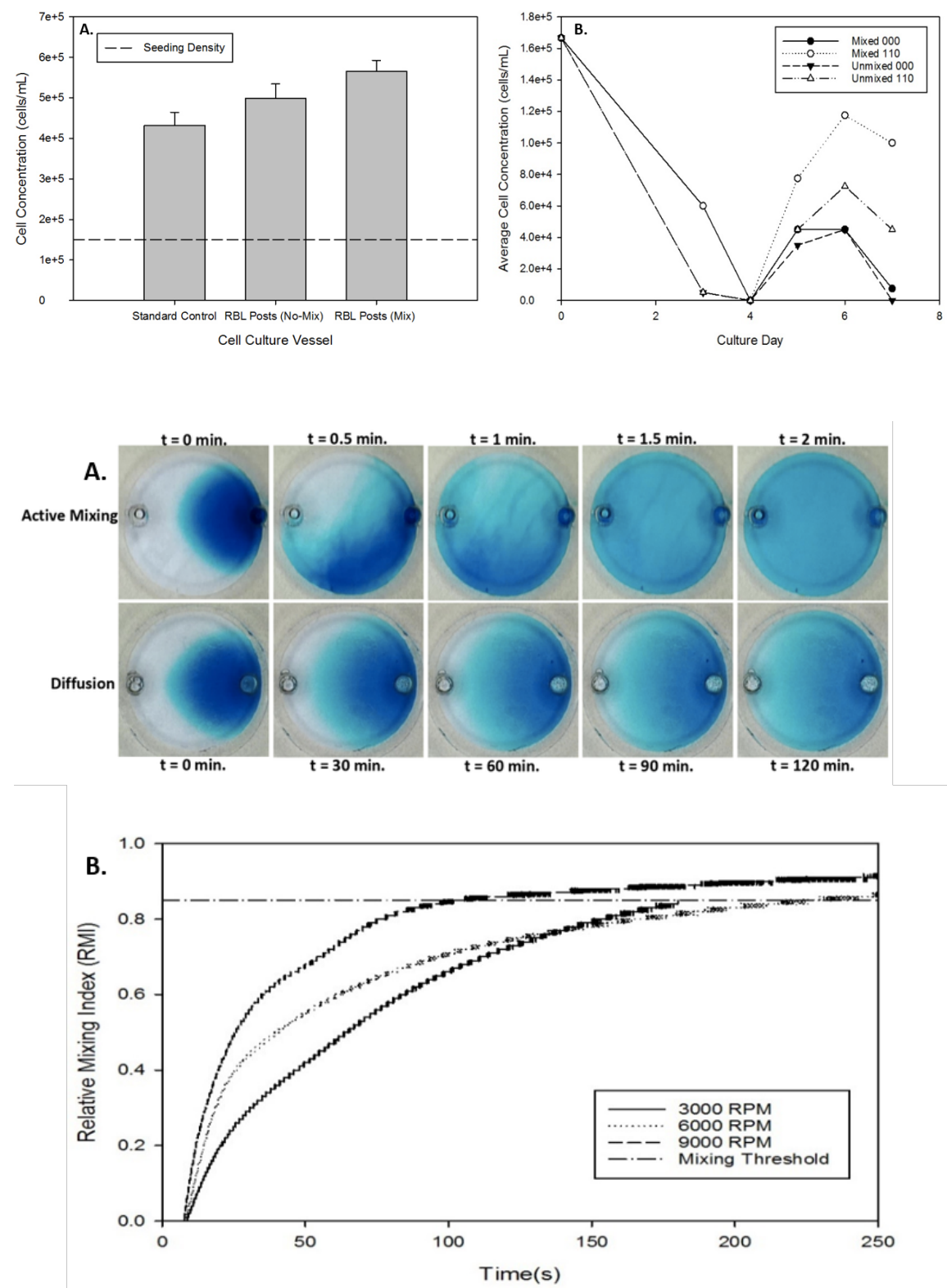